\title{
Ototoxicity of Toluene in Rats
}

\author{
MICHAEL J. SULLIVAN,${ }^{*} \dagger^{1}$ KYLE E. RAREY*2 AND RORY B. CONOLLY ${ }^{+3}$ \\ *Kresge Hearing Research Institute, $\dagger$ Toxicology Program, School of Public Health \\ The University of Michigan, Ann Arbor, MI 48109
}

Received 7 October 1986

\begin{abstract}
SULLIVAN, M. J., K. E. RAREY AND R. B. CONOLLY. Ototoxicity of toluene in rats. NEUROTOXICOL TERATOL 10(6) 525-530, 1988.-Toluene is a major industrial solvent and substance of abuse which is ototoxic in rats as shown by both behavioral testing and measurement of brainstem auditory evoked response (BAER) thresholds. The objective of this investigation was to examine the morphological (hair cell loss) and functional (BAER threshold elevations) changes resulting from toluene administration. In the preliminary experiment, 5 male Sprague-Dawley rats were dosed by gavage to $0.5 \mathrm{ml}$ toluene $/ \mathrm{kg}$ body weight/day in corn oil for 21 days then consecutively to $1.0 \mathrm{ml}$ toluene $/ \mathrm{kg} /$ day for 21 days. In the main experiment, eight male Sprague-Dawley rats were dosed by gavage for eight weeks with $1.0 \mathrm{ml}$ toluene/kg body weight/day in corn oil. Five and six control rats, respectively, received corn oil only. BAER thresholds were recorded from four toluene-treated and four control rats prior to dosing (main experiment) and from all rats after dosing (both experiments). Loss of outer hair cells occurred in all toluene-treated rats in the middle and basal turns of the organ of Corti, with the greatest loss in the third row and progressively less in the second and first rows. This loss was more severe in toluene-treated rats that demonstrated elevated BAER thresholds in midfrequency regions, typically $2-8 \mathrm{kHz}$. These experiments demonstrate that auditory changes are associated with cochlear hair cell loss in toluene-treated rats. These ototoxic effects of toluene contrast with those of other known ototoxicants, e.g., aminoglycoside antibiotics, in terms of the position of hair cell lesion in the organ of Corti and in the pattern of hair cell loss.
\end{abstract}

Toluene Ototoxicity Rats BAER Hair cells

TOLUENE is a major intermediate in the synthesis of commercial and industrial products $(2,5,8)$. The current Permissible Exposure Limit (9) for toluene is 200 ppm while the Threshold Limit Value (1) is $100 \mathrm{ppm}$. Toluene is also the substance of abuse in solvents and adhesives $(2,5,8)$. Hearing loss in humans has been reported associated with toluene exposure through chronic glue sniffing (4). Recent studies have described auditory threshold elevations following toluene exposure. Rats exposed to toluene vapor exhibited elevations of auditory thresholds as recorded by both behavioral testing (11) and measurement of brainstem auditory evoked response, BAER (12). These authors (10) have reported preliminary morphological examinations of cochleas from toluene-treated rats showing hair cell loss in the basal turn. These present studies were undertaken to determine whether inner ear lesions, defined by hair cell loss severity and position in the cochlea, are associated with the frequency-specific, toluene-induced auditory changes in the rat.

\section{METHOD}

\section{Chemicals}

Analytical grade toluene (Sigma Chemical Co., St. Louis, MO) was used in these investigations. Toluene dosing solu- tions, formulated at $0.5 \mathrm{ml}$ toluene/ $\mathrm{ml}$ corn oil, were made fresh daily in a $25.00 \mathrm{ml}$ volumetric flask. All other reagents were analytical grade unless noted.

\section{Animals}

Male Sprague-Dawley rats (initial weight 175-200 g, Charles River Laboratories, Inc., Portage, MI) were housed two per cage in hanging metal cages and given water and rodent chow (Ralston Purina Co.) ad lib. The animal quarters were maintained at $22^{\circ} \mathrm{C}$, on a 12 hour light/dark cycle. Rats were acclimatized for one week prior to use. Daily background noise exposure levels were monitored and found to be below $60 \mathrm{~dB}$ (SPL). Body weights were recorded each day. Liver and kidney weights were recorded at time of sacrifice and organ weight/body weight ratios calculated as measures of general toxicity.

\section{Preliminary Experiment}

Five rats were dosed by gavage with $0.5 \mathrm{ml}$ toluene $/ \mathrm{kg}$ body weight (b.wt.) for 21 consecutive days and then to 1.0 $\mathrm{ml}$ toluene/kg b.wt. for another 21 consecutive days. Five control rats received $1.0 \mathrm{ml} / \mathrm{kg} \mathrm{b}$.wt. of the vehicle, corn oil. On day 1 postadministration, BAER thresholds were recorded and the rats were then killed by decapitaton.

\footnotetext{
${ }^{1}$ Requests for reprints should be addressed to Michael J. Sullivan, Ph.D., at his present address: Environmental Assessment Research, Inc., P.O. Box 621, Newbury Park, CA 91320.

${ }^{2}$ Present address: Department of Anatomy, University of Florida, Gainsville, FL 32610.

${ }^{3}$ Present address: Northrup Services Inc., Environmental Sciences, 101 Woodman Dr., Suite 12, Dayton, OH 45431.
} 

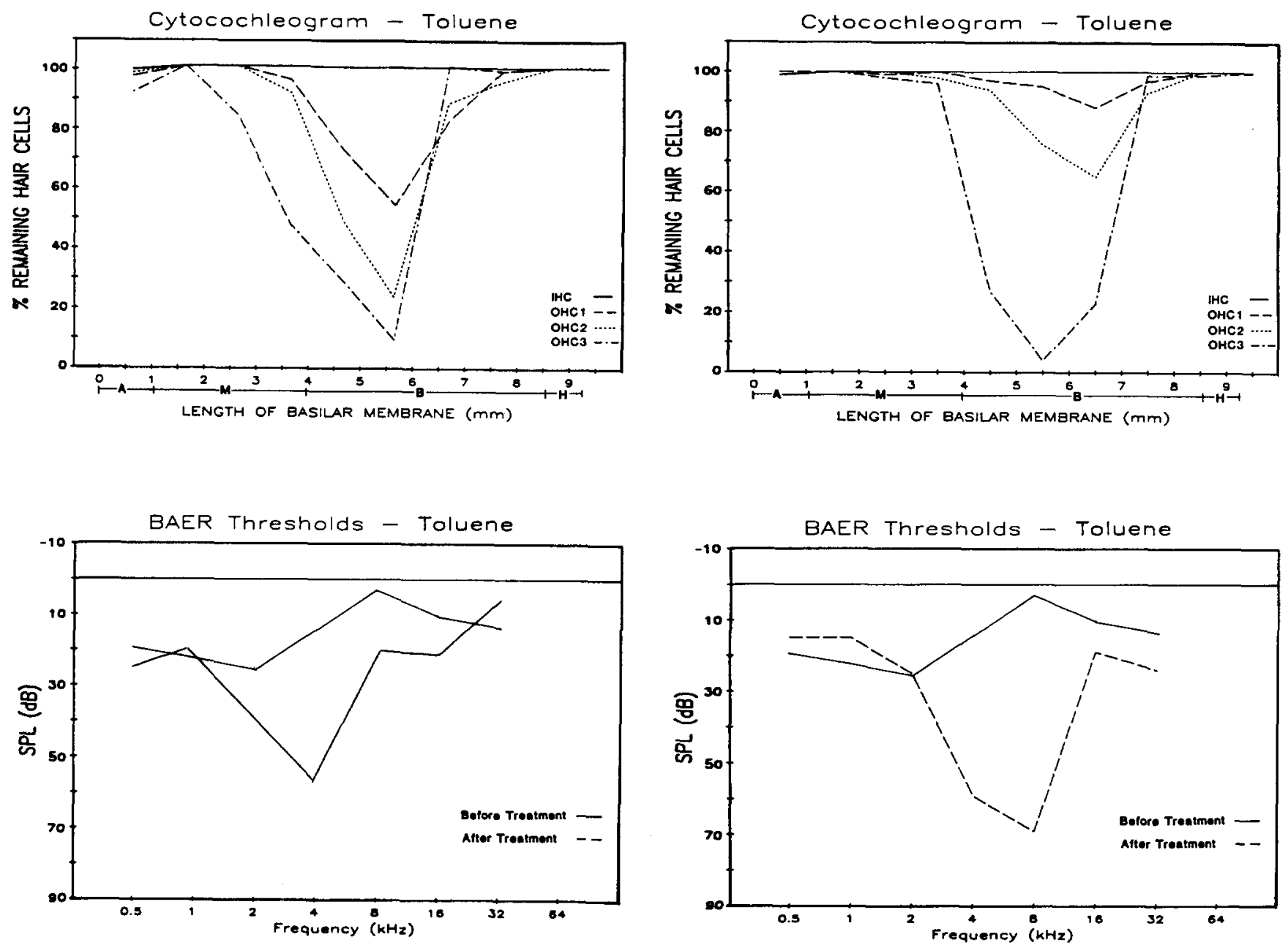

FIG. 1. Cytocochleogram and BAER threshold graph from a rat treated with $0.5 \mathrm{ml}$ toluene $/ \mathrm{kg}$ for 21 days then with $1.0 \mathrm{ml}$ toluene $/ \mathrm{kg}$ for 21 days (preliminary experiment) and sacrificed on day 1 after dosing ended. IHC, OHC1, OHC2 and OHC3 represent inner hair cells and outer hair cell rows 1,2 and 3 , respectively. A, M, B and $\mathbf{H}$ indicates apical, middle, basal and hook turns of the cochlea, respectively.

\section{Main Experiment}

Eight rats were dosed by gavage for 49 consecutive days with $1.0 \mathrm{ml}$ toluene/kg b.wt. Six control rats received 1.0 $\mathrm{ml} / \mathrm{kg} \mathrm{b}$.wt. of the vehicle, corn oil. BAER thresholds were recorded from 4 toluene-treated and 4 control rats prior to the beginning of dosing and from each rat on day 1 postadministration and the rats were then killed by decapitation.

\section{Functional Measure}

BAER thresholds were recorded in a sound attenuated box. Rats were anesthetized with an intraperitoneal injection of ketamine hydrochloride (Ketaset, $50 \mathrm{mg} / \mathrm{kg}$ ) and xylazine (Rompum, $10 \mathrm{mg} / \mathrm{kg}$ ). Additional doses ( $1 / 4$ original dose) were given as needed to maintain a stable state of anesthesia. The recording electrode configuration consisted of three small (26 gauge) hypodermic needles placed under the skin below the ipsilateral right pinna (reference electrode), at the

FIG. 2. Cytocochleogram and BAER threshold graph from a rat treated with $1.0 \mathrm{ml}$ toluene $/ \mathrm{kg}$ for 49 days (main experiment) and sacrificed on day 1 after dosing ended. ICH, OHC1, OHC2 and $\mathrm{OHC} 3$ represent inner hair cells and outer hair cell rows 1,2 and 3 , respectively. A, M, B and $\mathrm{H}$ indicate apical, middle, basal and hook turns of the cochlea, respectively.

vertex (active electrode) and below the contralateral pinna (ground electrode). The electrodes were connected to an amplifer (Grass, model P15D, gain=11, filter settings $=100-3 \mathrm{kHz}$ ). A digital signal averager (Tracor Northern, model TN-1500) was used for signal averaging. The acoustic stimuli were presented in a closed acoustic system via a $1 / 2^{\prime \prime}$ condensor microphone (Bruel and Kjaer) mated to a brass coupler with an $8.5 \mathrm{~cm} \times 0.3 \mathrm{~cm}$ (i.d.) silastic tube inserted into the left external auditory meatus. Thresholds were obtained to tone bursts with a $10 \mathrm{msec}$ duration, 1.0 msec rise time, at $32,16,8,4,2,1$ and $0.5 \mathrm{kHz}$. The stimulus repetition rate was $2 / \mathrm{sec}$. The stimulus intensity was decreased in $5 \mathrm{~dB}$ steps, beginning at $90 \mathrm{~dB}$ (SPL). One set of 64 stimuli presentations were given at each intensity at 3 sets were given to determine threshold. Stimulus intensities were calibrated using a wave analyzer (Hewlett and Packard). The overall shape of the waveform and the amplitude of wave 4 were followed as the response. In addition, peak latencies and peak-to-peak intervals were monitored as indicators of 

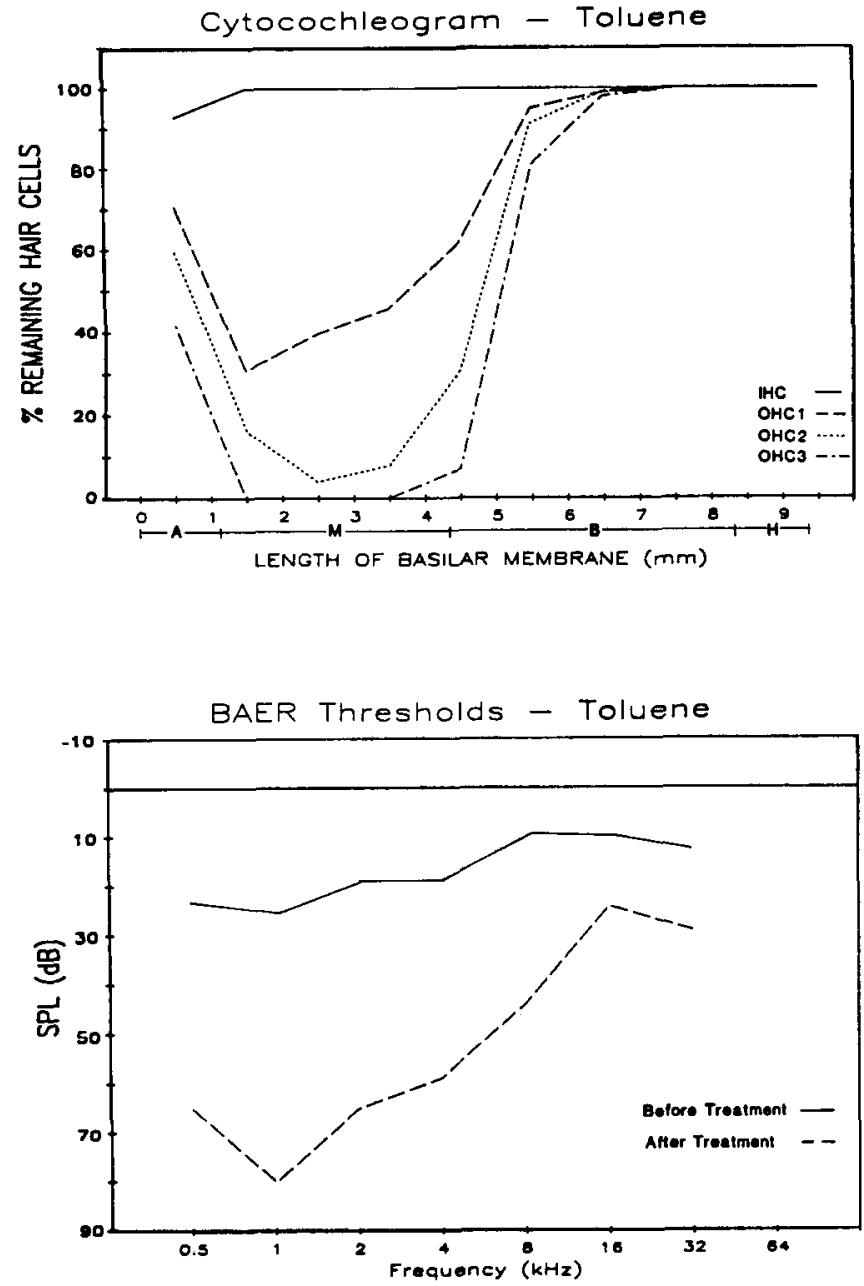

FIG. 3. Cytocochleogram and BAER threshold graph from a rat treated with $1.0 \mathrm{ml}$ toluene $/ \mathrm{kg}$ for 49 days (main experiment) and sacrificed on day 1 after dosing ended. IHC, OHC1, OHC2 and OHC 3 represent inner hair cells and outer hair cell rows 1, 2 and 3, respectively. A, M, B and $\mathrm{H}$ indicate apical, middle, basal and hook turns of the cochlea, respectively.

the integrity of the waveform. The attenuator setting (stimulus intensity) at which this response was last evident was recorded as threshold. BAER data for each animal were plotted as threshold intensity, dB (SPL), versus stimulus frequency. Posttreatment thresholds were compared to either pretreatment or average control posttreatment thresholds, as appropriate. The BAER threshold increases were then summed for each rat across the 7 frequencies tested and used as a measure of overall functional response for comparison with morphological response.

\section{Morphological Measure}

Both temporal bones were immediately removed after decapitation and the auditory bulla opened. The round and oval windows and the apex of the cochlea were opened with a cowhorn explorer. Within four minutes of decapitation, inner ear tissues were fixed by perfusing phosphate buffered (pH 7.4) 2.5\% glutaraldehyde solution through both windows and placing the tissue in a $20 \mathrm{ml}$ glass vial on a $14^{\prime \prime}$ rotor at 12
TABLE 1

SUMMARY OF FUNCTIONAL AND MORPHOLOGICAL MEASURES OF TOLUENE-INDUCED OTOTOXICITY

Rat No. Morphological Measure* Functional Measure ${ }^{*}$

\begin{tabular}{lrr}
\hline 1 & 24 & 77 \\
$2 \ddagger$ & 17 & 185 \\
3 & 21 & 117 \\
48 & 42 & 315 \\
5 & 7 & 40 \\
6 & 13 & 47 \\
7 & 11 & 29 \\
8 & 19 & 135 \\
\hline
\end{tabular}

*Percentage of area above the summary cochleogram.

† Summed BAER threshold elevations, dB, over 7 frequencies.

$\$$ Data from this animal in Fig. 1a,b.

$\$ D$ ata from this animal in Fig. $2 a, b$.

rpm on a $30^{\circ}$ angle for one hour. The tissue was then postfixed with a phosphate buffered $\left(\mathrm{pH} \mathrm{7.4)} 1 \% \mathrm{OsO}_{4}\right.$ solution in a similar manner for $\mathbf{3 0}$ minutes. Left (auditory tested) cochleas were microdissected (6) and right cochleas (nontested) were stored for microdissection, if needed. Individual turns of the organ of Corti were mounted on glass microscope slides in glycerol. Sensory hair cells were counted under a phase-contrast microscope (Wild, model M-20) equipped with a $50 \times$ objective. Cytocochleograms were made by plotting the percentage of hair cells remaining in each individual row, millimeter by millimeter, against distance $(\mathrm{mm})$ along the basilar membrane measured from apex. Summary cytocochleograms were prepared for each rat by graphing the percentage of all hair cells remaining against distance along the basilar membrane. The area above this curve, representing a measure of morphological response, was calculated. BAER threshold data and cytocochleograms were compared in terms of frequency of threshold elevations and position of the sensory hair cell loss along the basilar membrane.

\section{Statistical Analyses}

(Main experiment only.) Student's $t$-test was used to compare organ/body weight ratios. Analysis of variance (3) was used to compare the morphological measure of response between toluene-treated and control groups. Regression and coefficient of correlation analyses (3) were used to characterize the relationship between functional and morphological measures of response within the toluene-treated group. Analysis of covariance (13) was used to compare regression lines for body weight gain. The level of significance in all tests was $p<0.05$.

\section{RESULTS}

Losses of outer hair cells were observed in all toluenetreated rats (both experiments). The losses observed in the main experiment were significantly different from controls, $F(1,12)=11.83, p<0.01$. No treatment-related inner hair cell loss was seen. Cytocochleograms from three representative toluene-dose animals (one preliminary experiment and two main experiment) are shown in Figs. 1a, 2a and 3a, respectively. 

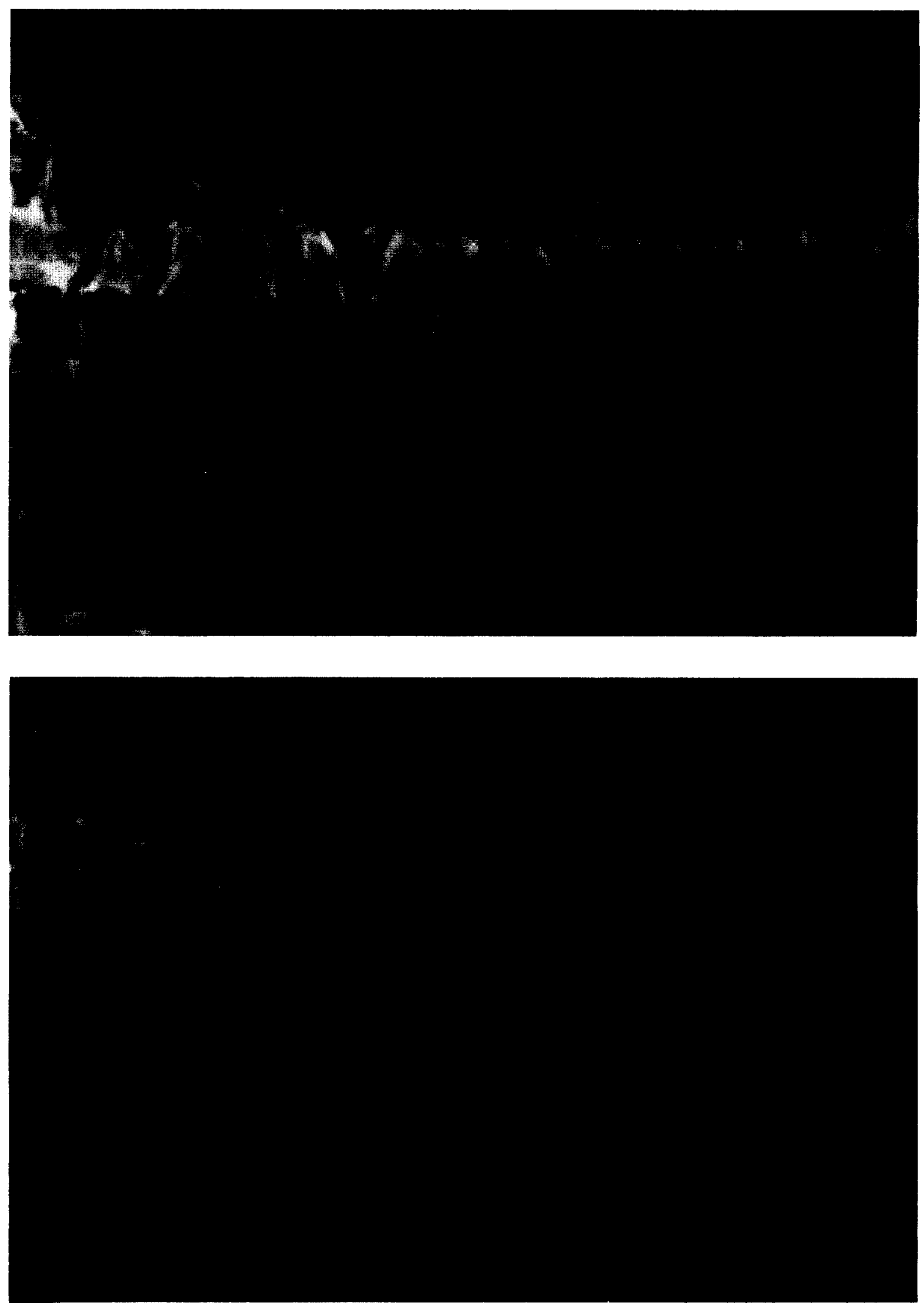


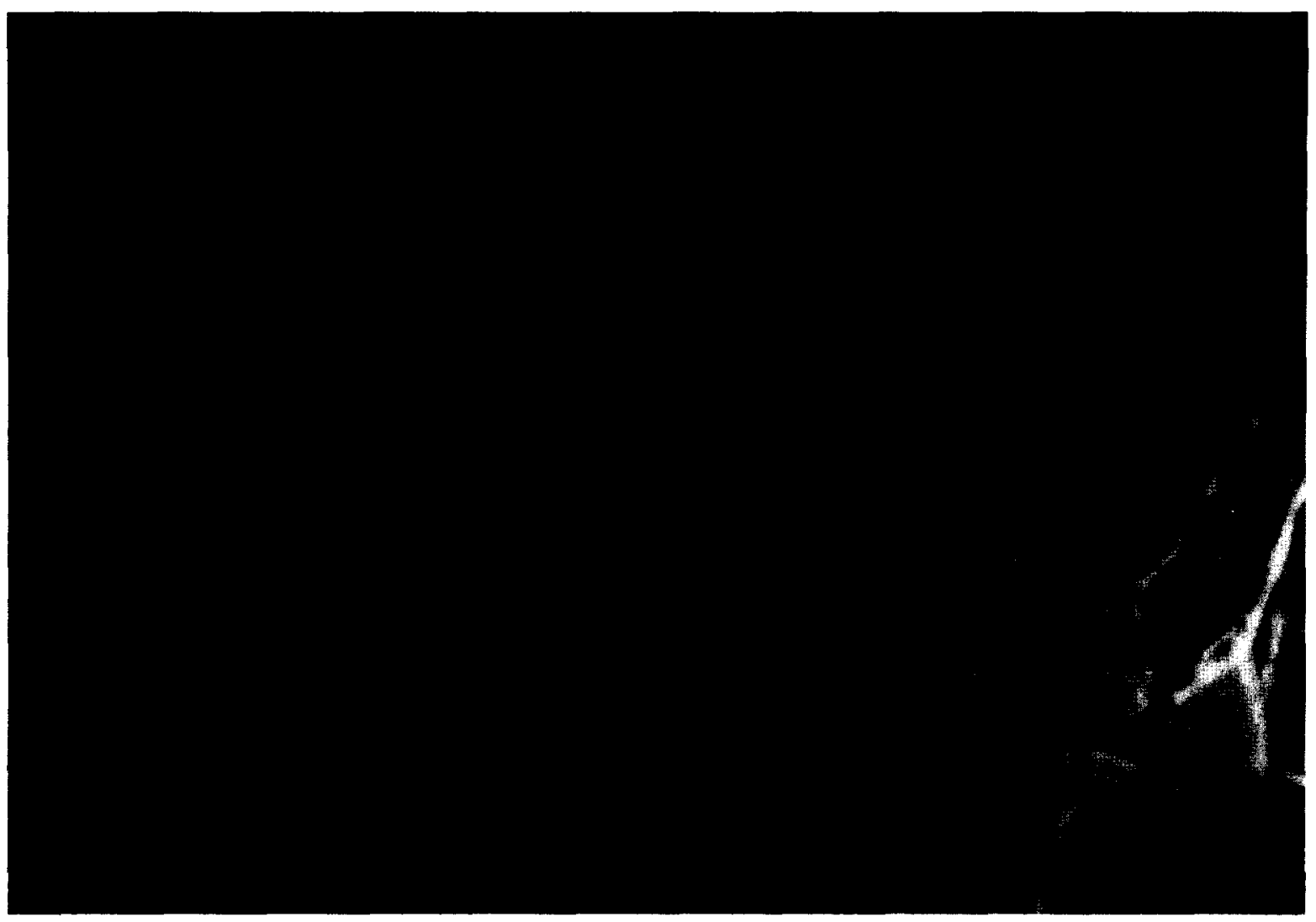

\section{THIS AND FACING PAGE}

FIG. 4. Photomicrographs of the organ of Corti from (a) control and ( $b$ and c) toluene-treated animals (main experiment). In b, arrows point to damaged outer hair cells. In $c$, arrows point out the few remaining outer hair cells. Magnification $=650 \times$.

The 8 toluene-treated rats of the main experiment exhibited a range of hair cell loss. From this range of responses, the lesion appears to begin in the middle and upper base turn and progress towards the apical region. In the least severe lesions, outer hair cell loss was confined to a narrow region of the lower middle turn/upper base turn of the organ of Corti. In the moderately severe lesions, exemplified by Fig. $2 \mathrm{a}$, hair cell loss was limited to the middle and base turns. In the more severe lesions, exemplified by Fig. 3a, the apical as well as middle and base turns are affected. The five rats of the preliminary experiment exhibited similar tolueneinduced hair cell lesions. Summarized morphological responses for the toluene-treated rats of the main experiment are presented in Table 1. Photomicrographs of the organ of Corti are presented in Fig. 4. In contrast to control tissue, Fig. 4a, in which all four rows of hair cells and supporting cells were present, the toluene-induced lesion was manifested by scarring of third row outer hair cells (Fig. 4b). In more severely damaged tissue, all three rows of outer cells became scarred (Fig 4c). Inner hair cells and pillar cells appear intact.

Frequency-specific BAER threshold elevations, corresponding to regions of the organ of Corti which had outer hair cell loss, were observed in toluene-treated rats. The greatest threshold elevations, up to $60 \mathrm{~dB}$ (SPL), occurred in the midfrequency regions, typically at $2-8 \mathrm{kHz}$. BAER threshold data from three representative toluene-treated rats (on preliminary experiment and two main experiment) are shown in Figs. $1 b, 2 b$ and $3 b$, respectively. Cytocochleograms and BAER threshold graphs are arranged so as to match the length of the basilar membrane with the frequency range of the rat. The standard error of control BAER thresholds shifts of less than $10 \mathrm{~dB}$ (SPL) were recorded in control rats and were not considered significant.

Summary data of functional and morphological measures of response in toluene-treated animals from the main experiments are presented in Table 1. Functional measure, summed BAER threshold increases, is listed with the morphological measure, percent area above the summary cytocochleogram. The rats which had the greatest hair cell loss also exhibited the greatest threshold elevations. If these measures are plotted as functional versus morphological, the coefficient of correlation (3), $r$, is .74.

There was no difference in organ weight/body weight ratios between control and toluene-treated groups for either liver or kidney. Toluene-dosed rats (main experiment) had a 
$16 \%$ depression of body weight gain throughout the study period and this was significantly different from the controls.

\section{DISCUSSION}

Selective outer hair cell loss was observed in the middle and upper basal turns of the cochleas of all toluene-treated rats (both experiments). BAER threshold elevations in the midfrequency regions of the cochlea, typically $2-8 \mathrm{kHz}$, wcre rccorded in the toluene-treated rats. There is a measured correlation between increasing loss of outer hair cells and increasing BAER threshold elevations in toluene-treated rats. In addition, these data demonstrate that the BAER threshold elevations observed in toluene-treated rats are associated with morphological changes in the organ of Corti. These data also provide some information on the frequency-mapping of the rat cochlea, by identifying regions of the 2,4 and $8 \mathrm{kHz}$ octave bands as located in the middle and upper base turns of the cochlea. In the toluene-treated rats the third row of outer hair cells showed the greatest amount of damage, followed by the second row and then the first. This pattern of outer hair cell loss was consistent in all the toluene-treated rats and is unique for chemically-induced damage reported to date. With aminoglycoside antibiotics, for example, outer hair cell loss is generally greatest in the first row and diminishes from first to third rows (7). These data suggest that the mechanism of toluene-induced hair cell loss differs from that of the aminoglycosides.

Liver and kidney have been reported as target organs in toluene-induced toxicity $(2,5,8)$. Enzymatic changes and hepatomegaly has been associated with toluene exposure. In these experiments, there was no effect of toluene on liver weight/ or kidney weight/body weight ratios at the dose levels studied. The $16 \%$ lower body weight gain in comparison with that of the controls suggests that the dose of toluene used in the main experiment did stress the animals. Therefore, the toluene-induced ototoxicity in these experiments was not secondary to the other major target organ toxicities. The daily oral dose of $1.0 \mathrm{ml}$ toluene/kg body weight/day in the Sprague-Dawley rat, ototoxic when administered for 8 weeks, corresponds to a 6 hour inhalation exposure to 800 ppm toluene vapor (14). This level is approximately $4 \times$ greater than the current PEL for occupational exposure.

These studies differed from those previously reported $(11,12)$ in which high frequency threshold elevations, 12,16 and $20 \mathrm{kHz}$, were measured. This indicates a different position of the lesion within the cochlea than identified by BAER threshold elevations measured at lower frequencies in this study. These authors (10) have presented preliminary, nonquantitative morphological evidence for hair cell loss in the basal turn in cochleas from toluene-exposed rats. The differences between those studies and the experiments reported here could be a function of the route of exposure, inhalation vcrsus oral, the strain of rat used, Fisher-344 versus Sprague-Dawley, or the background environment noise to which the animals were exposed.

\section{ACKNOWLEDGEMENTS}

The authors wish to thank Dr. J.^M. Aran for his generous help with the electrophysiological measurements and Ms. Julie Davis for her instruction in microdisection and hair cell counting. Supported by Training Grant No. 5T32E70762, Program Project Grant No. NS-05785, and Research Grant NS-05065.

\section{REFERENCES}

1. American Conference of Governmental Industrial Hygienists. Threshold limit values and biological exposure indices for 1986-1987. Cincinnati, OH: ACGIH; 1986:31.

2. Benignus, V. A. Health effects of toluene: A review. Neurotoxicology $2: 567-588 ; 1981$.

3. Devore, J. L. Probability and statistics for engineering and the sciences. Monterey: Brooks/Cole Pub. Co.; 1982.

4. Ehyai, A.; Freemon, F. Progressive optic neuropathy and sensorineural hearing loss due to chronic glue sniffing. J. Neurol. Neurosurg. Psychiatry 46:349-351; 1983.

5. Fishbein, L. An overview of environmental and toxicological aspects of aromatic hydrocarbons. II. Toluene. Sci. Total Environ, 42:267-288; 1985.

6. Hawkins, J. E., Jr.; Johnsson, L-G. Microdissection and surface preparations of the inner ear. In: Smith, C. A.; Vernon, J. A., eds. Handbook of auditory and vestibular research methods. New York: Charles C. Thomas Pub.; 1976:5-51.

7. Hawkins, J. E., Jr.; Johnsson, L-G. Histopathology of cochlear and vestibular ototoxicity in laboratory animals. In: Smith, C. A.; Vernon, J. A., eds. Handbook of auditory and vestibular research methods. New York: Charles C. Thomas Pub.; 1976: 175-196.
8. Hayden, J. W.; Peterson, R. G.; Bruckner, J. V. Toxicology of toluene (methylbenzene): Review of current literature. Clin. Toxicol. 11(5):549-559; 1977.

9. Occupational Safety and Health Administration. Federal Register. 40:46206-46219, October 6; 1975.

10. Pryor, G. T.; Dickenson, J.; Feeney, E.; Rebert, C. S. Hearing loss in rats first exposed to toluene as weanlings or as young adults. Neurobehav. Toxicol. Teratol, 6:111-119; 1984.

11. Pryor, G. T.; Rebert, C. S.; Dickenson, J.; Feeney, E. M. Factors affecting toluene-induced ototoxicity in rats. Neurobehav. Toxicol. Teratol. 6:223-238; 1984.

12. Rebert, C. S.; Sorenson, S. S.; Howd, R. A.; Pryor, G. T. Toluene-induced hearing loss in rats evidenced by the brainstem auditory-evoked response. Neurobehav. Toxicol. Teratol. $5: 59-62 ; 1983$.

13. Snedecor, G. W.; Cochran, W. G. Comparison of regression lines. In: Snedecor, G. W.; Cochran, W. G., eds. Statistical method. 6th ed. Ames, IA: Iowa State University Press; 1972:433-436.

14. Sullivan, M. J.; Conolly, R. B. Comparison of blood toluene levels after inhalation and oral administration. Environ. Res. 45:64-70; 1988 . 